\title{
Marine mammal response operations during the Deepwater Horizon oil spill
}

\author{
Sarah M. Wilkin ${ }^{1, *}$, Teresa K. Rowles ${ }^{1}$, Elizabeth Stratton ${ }^{2}$, Nicole Adimey ${ }^{1}$, \\ Cara L. Field ${ }^{3}$, Sara Wissmann ${ }^{1}$, Gary Shigenaka ${ }^{4}$, Erin Fougères ${ }^{5}$, Blair Mase ${ }^{2}$, \\ Southeast Region Stranding Network ${ }^{2,5}$, Michael H. Ziccardi ${ }^{6}$
}

\author{
${ }^{1}$ National Marine Fisheries Service Office of Protected Resources, Silver Spring, MD 20910, USA \\ ${ }^{2}$ National Marine Fisheries Service Southeast Fisheries Science Center, Miami, FL 33149, USA \\ ${ }^{3}$ The Marine Mammal Center, Sausalito, CA 94965, USA \\ ${ }^{4}$ National Ocean Service Office of Response and Restoration, Seattle, WA 98115, USA \\ ${ }^{5}$ National Marine Fisheries Service Southeast Regional Office, St Petersburg, FL 33701, USA \\ ${ }^{6}$ Oiled Wildlife Care Network, Karen C. Drayer Wildlife Health Center, School of Veterinary Medicine, \\ University of California, Davis, CA 95616, USA
}

\begin{abstract}
When the Mississippi Canyon-252 Deepwater Horizon (DWH) oil spill occurred in April 2010 in the Gulf of Mexico, wildlife professionals were quickly mobilized to assess, recover, and treat oiled marine mammals as part of the Incident Response operating under the Unified Command. There were significant challenges associated with the crisis, including the sustained response to a prolonged, uncontrolled oil release (from a deepwater wellhead rather than a controllable and finite source like a tanker); the large geographic scale of the oiled area and thus the response effort; and ensuring effectiveness without the benefit of previous experience of cetacean response in oil spills. The response phase for this spill lasted from April 2010 to May 2011, and the mobilization of field teams resulted in the confirmation of 13 live and 178 dead stranded cetaceans across 4 states and offshore waters. Four primary care centers were coordinated to de-oil animals, and additional facilities and personnel were mobilized to augment and support the effort. Numerous protocols were implemented to ensure appropriate animal care as well as documentation and sample collection, informing both response and Natural Resource Damage Assessment decisions. Additional efforts included the implementation of a wildlife observer program integrated into oil recovery operations (skimming and in situ burns) and behavioral observations of nearshore cetaceans. The unprecedented effort resulted in the first rehabilitation of an oiled dolphin and the coordination of a very large-scale response, with important information collected, and lessons learned for future oil spills in marine mammal habitat.
\end{abstract}

KEY WORDS: Marine mammals · Oil spill response - Deepwater Horizon · Gulf of Mexico Cetaceans $\cdot$ Rehabilitation

\section{INTRODUCTION AND BACKGROUND}

\section{Marine mammals and oil spills}

When oil spills occur in the marine environment, many species of wildlife in that ecosystem may be either directly or indirectly impacted. The impacts of

\footnotetext{
${ }^{*}$ Corresponding author: sarah.wilkin@noaa.gov
}

spilled oil on birds are well known (Leighton 1993, Jessup \& Leighton 1996), and multiple experiences over time have resulted in the development of robust and detailed avian capture and care protocols (Tseng 1999, Mazet et al. 2002, Massey 2006). In comparison, marine mammals (and, in particular, cetaceans and sirenians) have only infrequently been documented 
as being affected during oil spill incidents, resulting in less extensive readiness capabilities and 'wildlife response' efforts during spills.

Geraci \& St. Aubin (1990), Jessup \& Leighton (1996), and Johnson \& Ziccardi (2006) summarized the little that was known about the effects of oil on cetaceans prior to the MC-252/Deepwater Horizon (DWH) oil spill in 2010. Early behavioral studies conducted with captive cetaceans indicated that they were able to detect and actively avoid oil slicks on the surface of the water (Smith et al. 1983, Geraci 1990). However, observations in actual spills in the marine environment have demonstrated that larger whales (both mysticetes and odontocetes) and smaller delphinids do not avoid oil, with observations of animals traveling through and feeding in oil slicks (Grose \& Mattson 1977, Goodale et al. 1979, Matkin et al. 1994, Smultea \& Wursig 1995, Aichinger Dias 2017, this Theme Section).

While sightings of cetaceans during oil spills have been limited, and generally from aircraft, assessment of the physiological and toxicological impacts or effects of spills on marine mammals has been virtually nil. Prior to DWH, focused efforts to find, recover, and investigate stranded cetaceans in the vicinity of an oil spill were very limited. Without such effort in response, it has been difficult to determine if these animals were oiled or compromised due to the oil, limiting our understanding of impacts of oil and the potential mitigation measures that could be implemented during a response. Generally, only small numbers of cetaceans have been opportunistically found stranded coincident with oil spills (summarized by Geraci 1990 for spills prior to 1990; see also MMS 1983, Harvey \& Dahlheim 1994, Loughlin 1994, Zimmerman et al. 1995, Ozturk 2002).

For sirenians, even less experimental or anecdotal information is available, with only scant reports of impacts on manatees and dugongs (Loritz 1991, FigueroaOliver et al. 2000). For example, during the Iran-Iraq war in 1983, 53 dugong carcasses were recovered, but no detailed examinations of the carcasses were conducted (St. Aubin \& Lounsbury 1988). Overall, the impact of oil on sirenians is largely unknown (O'Hara \& O'Shea 2001) and, outside of these few anecdotal reports, no information is available on the pathophysiology and toxicology of oil exposure in sirenians.

\section{Marine mammals in the Gulf of Mexico}

Twenty-one species of cetaceans and 1 species of sirenian are found in the northern Gulf of Mexico
(GoM), with 2 (sperm whale Physeter macrocephalus and West Indian manatee Trichechus manatus) currently listed as endangered under the US Endangered Species Act, triggering additional US regulatory protections. Reports of marine mammals in the GoM that are sick, injured, out of habitat, in distress, or dead ('stranded') are responded to by organizations within defined marine mammal stranding networks, administered separately by the National Oceanic and Atmospheric Administration's National Marine Fisheries Service (NOAA/NMFS) for cetaceans and the US Fish and Wildlife Service (USFWS) for manatees.

The Marine Mammal Health and Stranding Response Program (MMHSRP), which was formalized in the 1992 Amendments to the Marine Mammal Protection Act (MMPA), is operated by NMFS to address concerns related to marine mammal health through national program components and regional implementation. The NMFS Regional Stranding Network in the GoM consists of volunteer network member organizations, including state agencies, non-profit organizations, academic institutions, and federal laboratories that are organized, authorized, and administered through Stranding Agreements issued by NMFS's Southeast Regional Office (or other authorizations for government agencies) and coordinated by the NMFS Southeast Fisheries Science Center in Florida. Trained network partners respond to and investigate live or dead stranded cetaceans, with some organizations providing rehabilitation for sick or injured cetaceans. In the northern GoM (Louisiana to the Florida Panhandle) at the time of the DWH oil spill, 5 primary organizations were responsible for stranding response within defined geographic areas; organizations typically work independently and only in their geographic area. The 2005-2009 annual average of cetacean strandings in the northern GoM region was 54 animals $\mathrm{yr}^{-1}$, with over $95 \%$ reported dead at time of stranding, and bottlenose dolphins representing $87 \%$ of the total (Venn-Watson et al. 2015).

For manatees, the USFWS has operated the Manatee Rescue and Rehabilitation Partnership (MRP) since 1973. Response effort for live and dead manatees has historically focused on primary manatee habitat in Florida. The 2005-2009 annual average for manatee responses throughout the United States was approximately 80 rescues of live animals (USFWS Manatee Database unpubl. data) and 350 recoveries of carcasses (FWC Mortality Database unpublished data), the vast majority of them in Florida. 


\section{Early DWH response (20 April to 31 May 2010)}

\section{Wildlife Branch}

Within the first week of the DWH response, a Wildlife Branch was activated within the Incident Command Post (ICP) established in Houma, Louisiana
(LA) (Fig. 1a). In consultation with NMFS (and for the first time in US oil spill efforts), a designated Marine Mammal and Sea Turtle Group (further divided into the Marine Mammal Unit [MMU] and the Sea Turtle Unit) was created within the Wildlife Branch, operationally separate from the other groups within the Wildlife Branch, namely Bird Stabilization/Rehabilita-
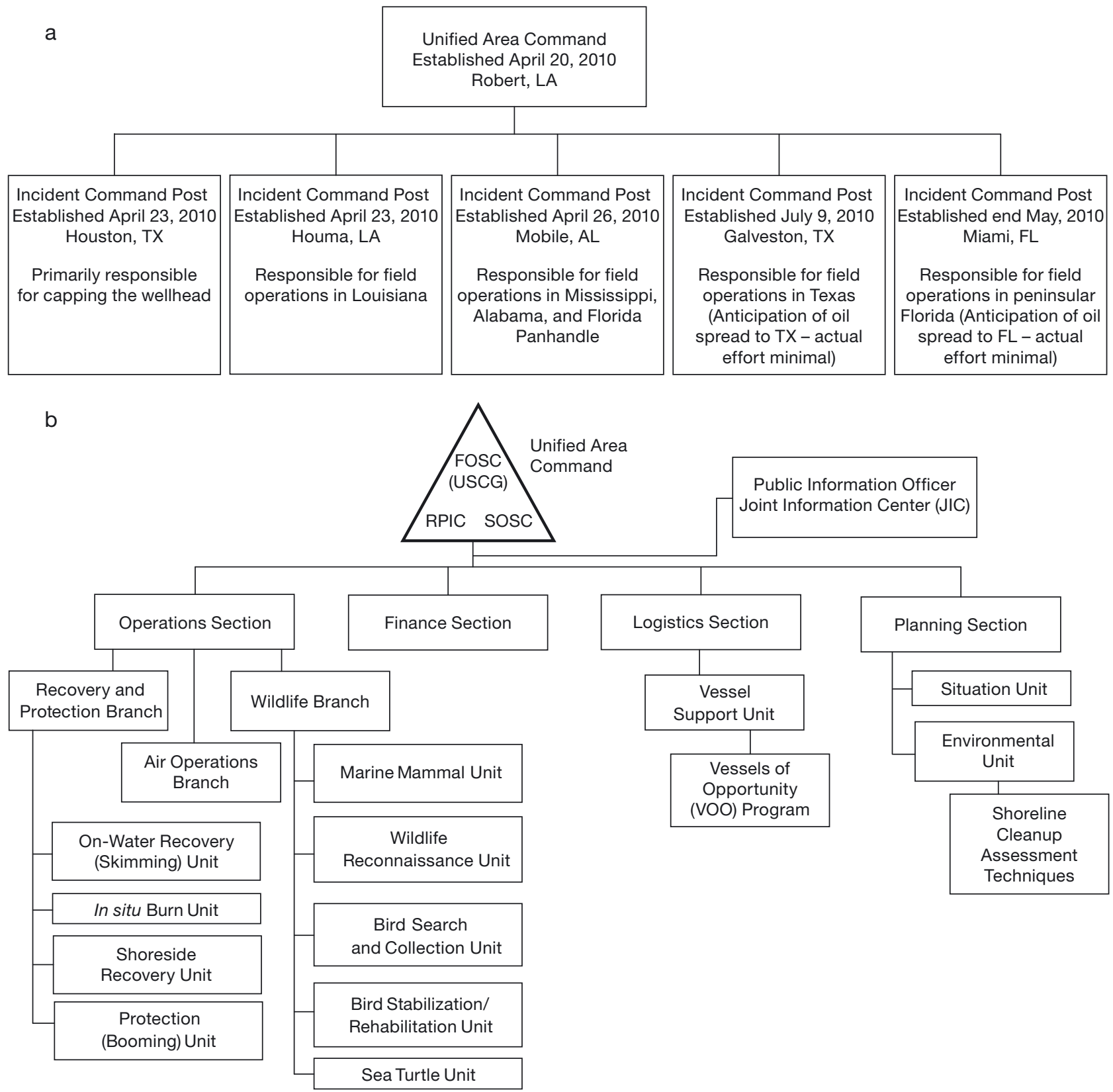

Fig. 1. Incident Command structure implemented for the Deepwater Horizon oil spill response. (a) Unified Area Command and 5 Incident Command Posts were established to divide the response geographically. LA: Louisiana; TX: Texas; AL: Alabama; FL: Florida. (b) Simplified Incident Command structure within each Incident Command Post, following the US Coast Guard (USCG) Incident management handbook, with expanded focus on the Wildlife Branch and groups that interacted with the Marine Mammal Unit. FOSC: Federal Onscene Coordinator; RPIC: Responsible Party Incident Commander; SOSC: State 
tion, Bird Search and Collection, and Wildlife Reconnaissance Units (Fig. 1b). Despite the later establishment of multiple ICPs for local management of activities (Fig. 1a), the MMU made the tactical decision to remain organized as a single unit managed from a single location, based in Houma, LA, with a marine mammal expert placed in the largely bird-centric Wildlife Branches in each additional ICP.

Personnel from the University of California at Davis (UCD), in collaboration with the MMHSRP, had developed National Guidelines for Oiled Marine Mammal Response (National Guidelines; Johnson \& Ziccardi 2006), and this document was used as the basis for initial guidance, as well as the overall marine mammal response plan. The MMU rapidly developed specific protocols for guiding experienced marine mammal responders with no prior oil spill experience, and for establishing efficient means of receiving reports of stranded marine mammals. A toll-free wildlife hotline was quickly established by the Unified Area Command (UAC) and widely promoted to responders, members of the public, and the media as a rapid mechanism for reporting any species of stranded or distressed wildlife in the northern GoM. The hotline was manned daily (from at least 06:00 to 18:00 h), information recorded on a standardized form, and immediately relayed to the MMU. Data were typically passed to the local stranding network organization within 30 min of receipt.

\section{MMU activities}

The initial reporting of marine mammals involved in the DWH spill began on 30 April 2010. Operational questions that arose in this early response phase, and the initial approach taken, included the following:

(1) How could marine mammal response best be incorporated into overall Wildlife Branch operations?

A Wildlife Management Plan was prepared for the incident and submitted to the UAC on 10 May 2010. This plan outlined the responsible authorities, organization of the Wildlife Branch, and general operational guidance at a high level for all impacted wildlife taxa, and incorporated the NOAA-NMFS National Guidelines to direct the response to, and care of, any affected marine mammals independent of, but in coordination with, bird response. The guidelines were significantly revised throughout the response to include manatees and further guidance on cetaceans.

(2) What should the geographic response area be for potentially impacted marine mammals?

Cetaceans are highly mobile at sea. As such, marine mammals (unlike birds) impacted within an oil slick may continue to swim and eventually strand in a location some distance away. Trajectory models were examined to estimate the extent of the oil slick, and a buffer zone extending beyond the oil boundary was applied to account for marine mammal movements post-oiling. The Designated Response Area (DRA) was initially defined as the Texas/Louisiana border eastward to the Alabama/Florida border, but was quickly expanded to include the Florida panhandle eastward to Apalachicola based on oil trajectory evaluation. Planning and preparatory activities took place outside the DRA, but strandings from these areas were not considered to be part of the official DWH response (see Table 2).

(3) What health and safety training should marine mammal field response and facility workers have?

The $24 \mathrm{~h}$ Hazardous Waste Operations and Emergency Response (HAZWOPER) training was deemed necessary for field workers but not required for facility (rehabilitation and necropsy) workers. The requirement for field workers was a significant consideration in mobilizing personnel, as most members of the marine mammal stranding network were not trained at this level at that time. Given the need to incorporate additional personnel but also satisfy mandated safety requirements, the Safety Officer arranged to have a HAZWOPER equivalency course $(3 \mathrm{~h})$ offered online.

(4) What resources (personnel, equipment, supplies, and facilities for recovery and rehabilitation of live and dead animals) are appropriate and available for marine mammal response?

Pre-existing and authorized marine mammal stranding network organizations in the northern GoM were mobilized in 1 of 2 roles: primary care (cleaning and rehabilitating oiled marine mammals) and field response (collecting animals from the field and transporting them to a primary care facility or necropsy laboratory; Table 1). Additionally, organizations with manatee expertise outside of the DRA were placed in an on-call status in the event that manatees were impacted. Finally, stranding network partners outside the northern GoM were identified to serve as secondary facilities that could complete the longterm rehabilitation of cetaceans following their deoiling and stabilization at a primary care facility. To prepare for increased needs (including personnel rotations to address fatigue), lists of additional personnel were also compiled from stranding partners outside the GoM, zoos, academia, and aquariums. Important contingency needs were identified, including additional temporary holding pools, increasing wash capabilities within permanent facilities, field 
Table 1. Marine mammal response organizations and care facilities activated for the Deepwater Horizon oil spill; na: not applicable

\begin{tabular}{|c|c|c|c|}
\hline Name & Location & Geographic response coverage & Role \\
\hline $\begin{array}{l}\text { Audubon Aquarium of } \\
\text { the Americas }\end{array}$ & New Orleans, Louisiana & Louisiana & $\begin{array}{l}\text { Primary care (cleaning } \\
\text { of oiled mammals) } \\
\text { Rehabilitation } \\
\text { Necropsy }\end{array}$ \\
\hline $\begin{array}{l}\text { Louisiana Department of } \\
\text { Wildlife and Fisheries }\end{array}$ & Throughout Louisiana & Louisiana & Field response \\
\hline $\begin{array}{l}\text { Institute for Marine } \\
\text { Mammal Studies }\end{array}$ & Gulfport, Mississippi & Mississippi and Alabama & $\begin{array}{l}\text { Primary care } \\
\text { Rehabilitation } \\
\text { Necropsy } \\
\text { Field response }\end{array}$ \\
\hline GulfWorld Marine Park & Panama City Beach, Florida & Florida Panhandle & $\begin{array}{l}\text { Primary care } \\
\text { Rehabilitation } \\
\text { Necropsy } \\
\text { Field response }\end{array}$ \\
\hline Emerald Coast Wildlife Refuge & Fort Walton Beach, Florida & Florida Panhandle & Field response \\
\hline SeaWorld Orlando & Orlando, Florida & On call & $\begin{array}{l}\text { Field response (manatees) } \\
\text { Rehabilitation (manatees) }\end{array}$ \\
\hline $\begin{array}{l}\text { Florida Fish and Wildlife } \\
\text { Conservation Commission }\end{array}$ & Throughout Florida & On call & Field response (manatees) \\
\hline Homosassa Springs State Park & Homosassa Springs, Florida & na & Rehabilitation (manatees) \\
\hline Lowry Park Zoo & Tampa, Florida & na & Rehabilitation (manatees) \\
\hline Miami Seaquarium & Miami, Florida & na & Rehabilitation (manatees) \\
\hline
\end{tabular}

equipment for transporting both live and dead mammals, and augmenting capacity to conduct full necropsies/sampling from all collected animals (including storage of carcasses/samples and collection of internal and external evidentiary samples).

(5) What were the appropriate, legally binding protocols for sample handling, collection, and storage (including chain of custody), as well as active surveillance for affected mammals?

The revised National Guidelines included cetacean recovery, rehabilitation, and sample and evidence collection procedures, as well as intake, care, necropsy, and chain of custody data forms. Significant efforts were made to physically confirm all reports of strandings. Responders examined animals and collected swab samples to detect external oiling or oil trapped in external orifices (e.g. mouth, blowhole, perineal area), and carcasses were collected and transported to laboratories, as logistically possible, for necropsy and further sampling. Live-stranded marine mammals that were evaluated on the beach by stranding network members were either transported to rehabilitation, immediately released, or humanely euthanized, depending upon the medical condition. Live animals that died on the beach, in transport, or in rehabilitation were necropsied and sampled.
(6) How should efforts be coordinated to collect the appropriate data on marine mammal sightings, behavior, clinical findings, and other information for response needs and also for use within the Natural Resource Damage Assessment (NRDA)?

Reconnaissance and Hotline data were used for response purposes and were also provided to the marine mammal NRDA Technical Working Group (TWG). Data forms and protocols were provided for NRDA review to confirm that data were being collected that would inform the NRDA/TWG efforts. It should be noted that the NRDA is a US legal requirement under the Oil Pollution Act. Similar post-spill ecological assessments may be conducted in other countries, and references to NRDA should be interpreted broadly in the international context.

(7) How would data be transmitted internally within the Incident Command System (ICS) and externally to the media (via the Joint Information Center) and other interested parties?

All marine mammals confirmed stranded within the DRA were documented in daily reports provided to the UAC. Animals were categorized as 'visibly oiled' (having evidence of oil externally or internally, including at necropsy for dead animals), 'not visibly oiled' (no evidence of oil externally or internally), or 
'pending' (cases that had not received a thorough examination upon recovery, or had not yet been necropsied). Once the examination of a 'pending' animal had been completed, animals were then moved to either 'visibly oiled' or 'not visibly oiled' category. Oiling status did not define cause of death, or indicate that the animal had or had not been impacted by the spill; the classification meant merely whether or not oil could be observed at the time of the examination.

\section{Animal summary for the early DWH time period}

From the beginning of marine mammal response operations on 30 April 2010 through 31 May 2010, 34 dead cetaceans were responded to, with 1 confirmed as being visibly oiled (Table 2). No live marine mammals were confirmed stranded during this initial response period.

\section{Intermediate DWH response (1 June to 31 August 2010)}

All marine mammal response efforts noted above continued during this time period, but with some additions as outlined in this section. A modified version of the marine mammal National Guidelines specific to the DWH spill was released to responders on 10 June 2010.
Wildlife observers

As the extent of clean-up operations expanded, concerns began to be raised regarding the potential for harassment, injury, and death of wildlife from onwater oil recovery activities - specifically in situ burning and skimming. As a result, specialized wildlife observers were hired, trained, and coordinated out of the Wildlife Branch providing observations and response for sea turtles, birds, and marine mammals. On 21 June 2010, an initial observer was placed within the in situ burn operations for a feasibility test that was deemed successful based upon the ability of the observer to become integrated into and monitor the operations. By 9 July 2010, enough observers had been deployed with the in situ burn task forces to provide $100 \%$ coverage for each ignition. Observers surveyed the area of the burn prior to oil collection, examined the area within the burn boom to ensure that no animals were contained within it, and continued to survey the surrounding area during and immediately following the burn. Observers were also placed on $25 \%$ of offshore skimming vessels, focusing on those vessels that represented the greatest risk to wildlife, either by virtue of their mode of operation or the area in which they were working. Observers on these trips surveyed the area around the skimming vessel as well as the oil inside the boom to ensure that there were no animals there, and were equipped and prepared to document all and rescue most animals in need of assistance. No marine mammals were observed within

Table 2. Live and dead cetacean strandings under the Deepwater Horizon (DWH) oil spill response; numbers reported as live I dead. VO: visibly oiled; NVO: not visibly oiled; blank cells indicate areas/times in which strandings were not considered to be part of the official DWH response activities; no manatee strandings occurred as part of official DWH response activities

\begin{tabular}{|c|c|c|c|c|c|c|c|c|c|c|c|c|}
\hline & \multicolumn{2}{|c|}{ Louisiana } & \multicolumn{2}{|c|}{ Mississippi } & \multicolumn{2}{|c|}{ Alabama } & \multicolumn{2}{|c|}{ Florida/Panhandle } & \multicolumn{2}{|c|}{ Offshore } & \multicolumn{2}{|c|}{ Total } \\
\hline & $\mathrm{VO}$ & NVO & VO & NVO & VO & NVO & VO & NVO & $\mathrm{VO}$ & NVO & $\mathrm{VO}$ & NVO \\
\hline Apr 2010 & $0 \mid 0$ & $0 \mid 0$ & $0 \mid 0$ & $0 \mid 0$ & $0 \mid 0$ & $0 \mid 0$ & $0 \mid 0$ & $0 \mid 0$ & $0 \mid 0$ & $0 \mid 0$ & $0 \mid 0$ & $0 \mid 0$ \\
\hline May 2010 & $0 \mid 1$ & $0 \mid 22$ & $0 \mid 0$ & $0 \mid 8$ & $0 \mid 0$ & $0 \mid 3$ & $0 \mid 0$ & $0 \mid 0$ & $0 \mid 0$ & $0 \mid 0$ & $0 \mid 1$ & $0 \mid 33$ \\
\hline Jun 2010 & $0 \mid 1$ & $1 \mid 11$ & $0 \mid 1$ & $0 \mid 5$ & $0 \mid 0$ & $1 \mid 2$ & $1 \mid 0$ & $2 \mid 1$ & $0 \mid 0$ & $0 \mid 1$ & $1 \mid 2$ & $4 \mid 20$ \\
\hline Jul 2010 & $0 \mid 0$ & $0 \mid 1$ & $0 \mid 0$ & $0 \mid 6$ & $0 \mid 0$ & $0 \mid 1$ & $0 \mid 0$ & $0 \mid 0$ & $0 \mid 0$ & $0 \mid 0$ & $0 \mid 0$ & $0 \mid 8$ \\
\hline Aug 2010 & $0 \mid 1$ & $1 \mid 12$ & $0 \mid 0$ & $0 \mid 3$ & $0 \mid 0$ & $0 \mid 0$ & $0 \mid 0$ & $1 \mid 0$ & $0 \mid 0$ & $1 \mid 0$ & $0 \mid 1$ & $3 \mid 15$ \\
\hline Sep 2010 & $1 \mid 0$ & $0 \mid 11$ & $0 \mid 0$ & $0 \mid 1$ & $0 \mid 0$ & $0 \mid 2$ & $0 \mid 0$ & $0 \mid 2$ & $0 \mid 0$ & $0 \mid 0$ & $1 \mid 0$ & $0 \mid 16$ \\
\hline Oct 2010 & $0 \mid 0$ & $0 \mid 2$ & $0 \mid 0$ & $0 \mid 3$ & $0 \mid 0$ & $0 \mid 0$ & $0 \mid 0$ & $0 \mid 0$ & $0 \mid 0$ & $0 \mid 0$ & $0 \mid 0$ & $0 \mid 5$ \\
\hline Nov 2010 & $0 \mid 0$ & $0 \mid 0$ & $0 \mid 0$ & $0 \mid 0$ & $0 \mid 0$ & $0 \mid 0$ & $0 \mid 0$ & $0 \mid 0$ & $0 \mid 0$ & $0 \mid 0$ & $0 \mid 0$ & $0 \mid 0$ \\
\hline Dec 2010 & $0 \mid 1$ & $1 \mid 3$ & & & & & & & & & $0 \mid 1$ & $1 \mid 3$ \\
\hline Jan 2011 & $0 \mid 1$ & 217 & & & & & & & & & $0 \mid 1$ & 217 \\
\hline Feb 2011 & $0 \mid 3$ & $0 \mid 19$ & & & & & & & & & $0 \mid 3$ & $0 \mid 19$ \\
\hline Mar 2011 & $0 \mid 1$ & $0 \mid 18$ & & & & & & & & & $0 \mid 1$ & $0 \mid 18$ \\
\hline Apr 2011 & $0 \mid 0$ & $0 \mid 14$ & & & & & & & & & $0 \mid 0$ & $0 \mid 14$ \\
\hline May 2011 & $0 \mid 0$ & $1 \mid 10$ & & & & & & & & & $0 \mid 0$ & $1 \mid 10$ \\
\hline Total & $1 \mid 9$ & $6 \mid 130$ & $0 \mid 1$ & $0 \mid 26$ & $0 \mid 0$ & $1 \mid 8$ & $1 \mid 0$ & $3 \mid 3$ & $0 \mid 0$ & $1 \mid 1$ & $2 \mid 10$ & $11 \mid 168$ \\
\hline Grand total & \multicolumn{2}{|c|}{$7 \mid 139$} & \multicolumn{2}{|c|}{$0 \mid 27$} & \multicolumn{2}{|c|}{$1 \mid 8$} & \multicolumn{2}{|c|}{$4 \mid 3$} & \multicolumn{2}{|c|}{$1 \mid 1$} & \multicolumn{2}{|c|}{$13 \mid 178$} \\
\hline
\end{tabular}


the in situ burn booms or in proximity to the skimming vessel, and no rescues of any wildlife were conducted by these offshore observers. Data collected by these observers on sightings of animals were routinely provided to the Wildlife Branch.

Rehabilitation of oiled cetaceans

The first live dolphin stranding occurred in the DRA on 2 June 2010. In total, 13 live-stranded dolphins representing 3 species were recovered under response (10 bottlenose dolphins Tursiops truncatus, 2 spinner dolphins Stenella longirostris, and 1 Clymene dolphin S. clymene; Table 3). In most cases, the dolphins were found isolated on or near a beach and unable or unwilling to swim away. Some of the live-stranded animals were immediately released at the site by trained responders after assessing the situation $(\mathrm{n}=3)$ or by members of the public without assessment ( $\mathrm{n}=2)$, and several either died $(\mathrm{n}=4)$ or were euthanized $(\mathrm{n}=1)$ after stranding. Three bottlenose dolphins rescued during response, including one that was externally visibly oiled, were brought into rehabilitation to the Audubon Aquarium of the Americas in Louisiana.

For all live-stranded cetaceans encountered by responders, initial clinical assessment was carried out in the field by a veterinarian. As potential exposure to oil was most likely to have occurred through inhalation, aspiration, ingestion, and/or direct contact, particular attention was directed to the respiratory and oral tracts, as well as the eyes and skin. Oil on animals was sampled in the field prior to excessive handling.

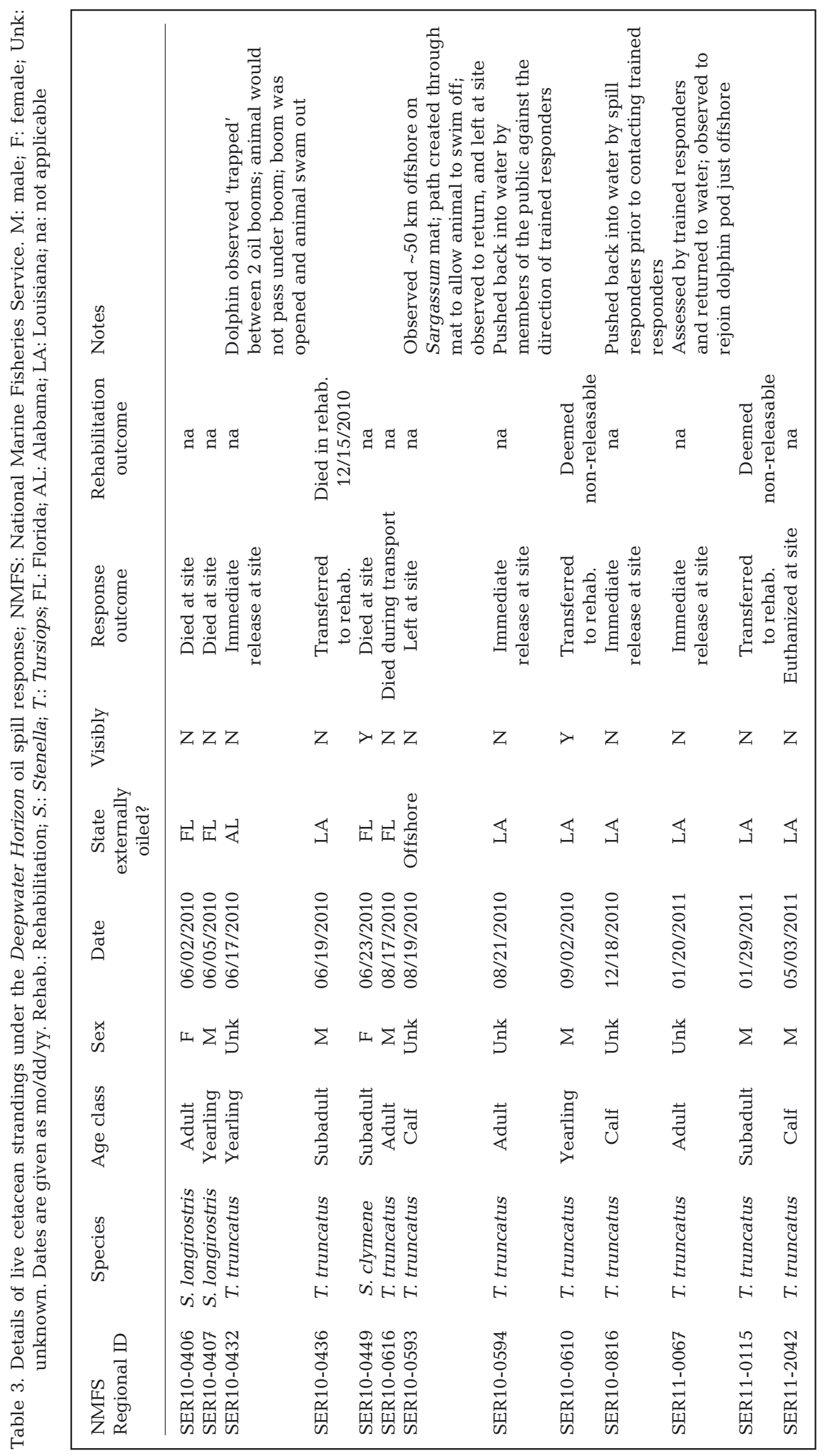


Generally, the live-stranded dolphins that were evaluated were lethargic and mildly to moderately dehydrated, consistent with most stranded cetaceans (Table 3). Blood was collected for routine complete blood count, serum chemistry analysis, and hydrocarbon evaluation, with basic chemistry and electrolyte parameters evaluated in the field with a point-of-care analyzer whenever possible. Treatment to correct electrolyte or other abnormalities was initiated in the field, when possible, in order to help stabilize the animal. Respiratory rate and quality, heart rate, vocalizations, and general movement were evaluated to assess response to handling and potential transport. Mild sedation with a benzodiazepine was required for 2 dolphins due to increased agitation associated with transport. Transport occurred either on an open flatbed truck or enclosed vehicle. Air temperature and movement in enclosed vehicles was controlled with high cool air flow and open windows to ensure adequate ventilation and appropriate temperature maintenance of suspected oiled animals.

One live-stranded dolphin (SER10-0610) was visibly oiled and required external de-oiling at the rehabilitation facility. Visible oil covered nearly the entire external surface and was concentrated around the anal and genital slits. No oil was visible in the blowhole, mouth, or eyes. The dolphin was cleaned prior to placement in a pool to minimize contamination of the facilities. A liberal amount of vegetable oil was applied to the entire skin surface to loosen the thick, sticky crude oil, which was then readily wiped off with absorbent, disposable towels. The skin was then washed with a liberal amount of Dawn ${ }^{\circledR}$ (Proctor and Gamble) liquid detergent and rinsed with fresh water before placing the dolphin in the saltwater rehabilitation pool. Feces were monitored by cytology for the presence of oil for the first day; however, no visible evidence of oil in the feces was noted.

For each of the 3 dolphins that underwent rehabilitation during response (SER10-0436, SER10-0610, and SER11-0115), further clinical evaluation and sampling for oil contamination was conducted on-site at the rehabilitation facility, and included evaluation of exhalation (chuff) samples, gastric fluid, and feces for oil contamination, parasites, and other anomalies. Thoracic radiographs of SER10-0610 were collected within the first few days following stranding, as pneumonia secondary to oil inhalation or other disease process was a concern; the other 2 dolphins were not radiographed. Visual examination of the blowhole and the blowhole cytology did not show evidence of oiling at the time of stranding in any of the 3 dolphins, and the dolphins exhibited no clinical findings that re- quired specific respiratory treatments while in rehabilitation. Two of the 3 dolphins undergoing rehabilitation were suspected to have gastrointestinal distress based on gastric sample cytology and abnormal appearance of feces, and the animal that died in care (SER10-0436) had ulcerations in the gastrointestinal tract. No visible oil was noted in the gastric or fecal samples taken from any of the 3 dolphins during the course of rehabilitation; therefore, it was unknown whether the clinical presentation was secondary to oil (which might have passed through the gastrointestinal tract prior to stranding) or other factors. Standard treatments with gastroprotectants, antimicrobials, and analgesics were administered as needed. All 3 dolphins showed initial regular clinical progress following transport, stabilization, and standard rehabilitation in each case. Unfortunately, SER10-0436 died in care after 6 mo of rehabilitation, and was later found to have meningoencephalitis secondary to Brucella infection upon necropsy. The other 2 dolphins (SER100610 and SER11-0115) were deemed non-releasable by NMFS due to their young age at time of stranding and were placed in permanent care facilities.

\section{Behavioral observations of potentially impacted cetaceans}

During intermediate response, relatively frequent reports were received of dolphins swimming in and near oil, with a concern that, although free-swimming, the animals may have been in distress and required assistance. While no free-swimming dolphins were ultimately captured and translocated or brought into rehabilitation, these reports were investigated whenever possible to verify the sighting, determine whether the animals were in distress, and recommend whether an intervention was warranted. Potential intervention options included hazing (i.e. deterrence) in an attempt to move the dolphins out of an area, or capture and relocation to an unoiled area or for rehabilitation.

One dedicated behavioral observation effort was conducted in the Perdido Bay, Alabama (AL), complex between June and August following public reports of concern for free-swimming dolphins. No evidence of animals in distress and in need of intervention was found. While these efforts were geographically limited during DWH, and did not result in the capture or hazing of dolphins, the methods are scalable for other spills where local populations of cetaceans warrant assessment and mitigation due to small populations, the characteristics of the spill, or other factors. The efforts also provided important real-time data to cali- 
brate response efforts, and an important means of community engagement for input and outreach.

Increased coordination outside of the Wildlife Branch

To supplement the dedicated marine mammal observation teams that were deployed by the Wildlife Branch, additional efforts were made in collaboration with the Shoreline Cleanup Assessment Technique (SCAT) teams and Vessel of Opportunity (VOO) program to increase timely reporting of live or dead stranded, or distressed marine mammals. External oil sample collection supplies and a protocol were provided to SCAT teams so they could document, sample, and mark (to prevent double counting) dead stranded animals. Animal information and samples were then provided to the Wildlife Branch at the end of each day under chain of custody procedures. For VOO operators, similar supplies and instructions were provided, but efforts were focused on calling in reports of oiled mammals to the Wildlife Hotline for further directed follow-up.

Non-traditional aerial platforms including a modified commercial A-1-70 series blimp were also used by the response, and a dedicated, trained wildlife observer was included on several days of reconnaissance. Although limited in scope, this successful integration of marine mammal objectives into air operations within the ICS may provide critical information in future spill situations.

Animals summary for the intermediate DWH time period

From 1 June to 31 August 2010, the MMU responded to a total of 54 marine mammals. Eight cetaceans were found alive, including 1 that was externally oiled. The remaining 46 cetaceans were dead, including 3 that were visibly oiled. Most of the strandings were in Louisiana, followed by Mississippi (Table 2).

\section{Late DWH response and demobilization (September to November 2010)}

\author{
Development of step-down/transition/ \\ de-escalation plan
}

A capping stack was installed on the wellhead on 15 July (US Department of Homeland Security 2011), which eliminated the fresh flow of oil and began the development of transition plans within each section/ branch to end response activities and complete transition to NRDA activities (which had been occurring in parallel to response up to this point). The Wildlife Branch plan was designated to guide remobilization of response activities should the conditions change and warrant wildlife response. Specifically, this plan provided:

- A tiered approach to the allocation of staff and response resources (number and location) for demobilization or remobilization

- Triggers (decision points) to guide changes to wildlife response, rehabilitation, assessment, and monitoring activities based on (1) number of strandings, locations, and degree of oiling of rescued and recovered marine mammals; (2) behavior and distribution of marine mammals observed in nearshore and offshore waters; (3) assessment of marine mammal habitat quality, including shoreline, nearshore, and offshore environments; and (4) best available environmental information

- Data for reporting to the UAC and federal and state wildlife trustee agencies to enable ongoing and long-term monitoring.

For the MMU, the criteria in the transition plan established that response efforts would step down to medium effort following $30 \mathrm{~d}$ with no confirmed oiled marine mammal strandings, and would transition out of response following $60 \mathrm{~d}$ with no confirmed oiled marine mammal strandings. An Expert Working Group (EWG) was established to provide advice on the scope and level of response needed if specified criteria were met (e.g. the stranding of a confirmed externally oiled marine mammal).

The Wildlife Branch Transition Plan was officially completed and signed by the UAC on 24 September 2010. Following the plan, marine mammal stranding response transitioned from high to medium effort on 2 October 2010, and the active marine mammal response effort was demobilized on 2 November 2010 throughout the DRA.

\section{Animal summary for the late DWH time period}

From 1 September to 2 November 2010, 22 marine mammals were recovered (Table 2). Only 1 recovered dolphin was found alive, but that dolphin, recovered on 2 September 2010, was externally oiled. The remaining collected cetaceans were found dead, with none being visibly oiled. 


\section{Remobilization (December 2010 to May 2011)}

On 3 December 2010 (30 d after complete demobilization), a dead bottlenose dolphin was found stranded at Grand Isle State Park, LA, with spots of external oil and a black substance in the cranial esophagus. Upon chemical analysis, the external sample was positively identified as a match to MC252/DWH oil. As a result, and upon the recommendation of the EWG, response was remobilized for central and eastern Louisiana (from St. Mary's Parish to the Louisiana/Mississippi border) for a period of $60 \mathrm{~d}$, per the step-down plan. Further cetacean strandings with confirmed DWH oil resulted in response being prolonged in this geographic area for an additional 173 d, until 25 May 2011, when Louisiana transitioned out of response following discussions with the EWG. However, individual oiled dolphins with a confirmed match to DWH oil continued sporadically, until the last confirmed match was detected in February 2012 (DWH NRDA Trustees 2016).

\section{DISCUSSION}

The scope and scale of the response to marine mammals during the DWH oil spill exceeded anything previously experienced in the USA. The response accomplished activities from the first-ever rehabilitation of an oiled dolphin to the effective coordination of stranding network efforts across 4 states to respond to the spill. Protocols that guided timely reporting of the correct information resulted in a rapid flow of accurate data to the UAC as well as trustee agencies, the media, and the general public. Protocols for all aspects of the marine mammal response were quickly and efficiently developed or modified from preexisting documents to meet the needs of the situations encountered; these protocols are available for use and modification in future spills, as needed (see Ziccardi et al. 2015).

Issues that were identified by the response included a relatively low preparedness level of the US marine mammal stranding network at the beginning of the spill, with most responders not having the required prerequisite training to be deployed immediately. Having a group of trained and qualified responders is critical to the success of any wildlife response; however, training for future events is very difficult to maintain, especially for those species requiring specialized animal handling expertise for daily interactions but infrequent needs for specialized oil spill response training.
Practical issues, including the significant additional burden of managing data and samples, chain of custody, and communications arose during the response and required additional personnel. In the future, additional personnel should be identified and deployed early in a response to focus on data and sample organization and communication, to ensure that numbers are accurate and samples are effectively archived for law enforcement and NRDA needs.

Having comprehensive protocols for all responders to refer to and modify as needed was a key element in ensuring a consistent and cohesive approach to marine mammal response. While these protocols were in place by the end of the response, their establishment for all species prior to the incident would have been of significant benefit. To this end, NMFS recently completed a thorough revision of its 2005 National Guidelines (Ziccardi et al. 2015) to include all cetaceans and pinnipeds, and these can serve as a template for the development of more specific regional plans or national/international plans and spillspecific action plans.

Integration of marine mammal needs into the overall ICS structure, particularly within the Wildlife Branch, Environmental Unit, and Joint Information Center (Fig. 1b), was also recognized as a critical element of this response and is an important goal for improvement for future responses. It was evident in the early phases of this response that the marine mammal and oil spill response communities were not familiar with the respective goals, missions, and cultures. Therefore, it is very important that marine mammal researchers, managers, and stranding networks worldwide, especially in areas at higher risk of spills, are encouraged to reach out to the oil spill response community locally, regionally, nationally, or internationally, and discuss coordination prior to any spill response. Inclusion of marine mammal response and impacts in oil spill drills, again on all geographic scales, would provide excellent opportunities for building awareness and collaboration between oil spill responders and marine mammal experts, as well as to test response protocols, operations, and communication.

Some of the new wildlife response techniques employed in this spill, such as the inclusion of observers for in situ burning and offshore skimming activities were successful and should be considered for future responses to inform and reduce further harm to marine mammals (or other wildlife) by providing realtime tactical information that could be used for mitigation during the immediate operational response. Additionally, expanded behavioral response obser- 
vations of non-stranded mammals can determine if intervention is warranted for coastal cetaceans, otters, and sirenians, but should also be extended to offshore cetaceans, including large whales and pinnipeds on rookeries and haul-outs, although intervention options are variable for these groups. Including these approaches in planning initiatives will enable faster implementation in future events. Another area for future improvement is the clarification of roles, responsibilities, and coordination between response (the activities reported in this paper and represented in Fig. 1) and the NRDA. Samples and data collected within response were intended to be used by NRDA, and efforts were made to create a seamless transition. The stranding information and samples collected (e.g. external oil sample, histopathology) were used by NRDA in many analyses, included in the Final Programmatic Damage Assessment and Restoration Plan (DWH NRDA Trustees 2016) and several published studies (e.g. Venn-Watson et al. 2015, Colegrove et al. 2016). Improved coordination between response and NRDA should be pursued as these activities are overlapping in both space and time, to ensure that all information is collected, organized, and communicated between the 2 groups. Additionally, the designation of the elevated cetacean stranding rate in the DRA as an unusual mortality event (UME, a legal process under the US MMPA), increased the complexity of sampling protocols, resulting in a more complicated assessment for the response organizations, but provided significant cross-disciplinary expertise for the investigation (for more on the northern GoM cetacean UME, with increased stranding rates which continued beyond the response phase through July 2014, see Litz et al. 2014, Venn-Watson et al. 2015, DWH NRDA Trustees 2016).

In conclusion, the marine mammal response operations during the DWH oil spill were considered largely successful, resulting in the documentation of 13 live and 168 dead cetaceans in the northern GoM. After the active response phase ended, stranding investigations continued as part of the NRDA and UME processes. A multi-partner network was augmented and supported to allow coordinated response efforts across 4 states. Information and samples collected were used as legal evidence and to improve scientific understanding of the impacts of oil on marine mammals. Finally, while we hope that a response to an oil spill on this scale is not needed in the future, if and when it does prove necessary, the protocols and procedures that were created, tested, and refined in this spill could be quickly modified, adopted, and deployed.
Acknowledgements. We acknowledge all of the Marine Mammal and Sea Turtle Group responders during the 14 mo of the Response phase. To the individuals, many of whom were far from home, and who responded in the field in oppressive heat, humidity, thunderstorms, and tropical storms; the facility staff who cared for animals in rehab, conducted necropsies, and filled out a countless chain of custody forms; all who served a rotation (or multiple rotations!) in the command posts learning new and creative ways to fill out ICS forms; the trustee agency staff who filtered the requests for information and reformatting of data into yet another table; our colleagues in the other aspects of the response - our sincere thanks and acknowledgement. The findings and conclusions in this paper are those of the authors and do not necessarily represent the view of NOAA or of any other natural resource Trustee for the BP/DWH NRDA or the Unified (Area) Command. Funding for the marine mammal response was provided by BP as part of their obligation as the responsible party for the MC-252/ DWH oil spill.

\section{LITERATURE CITED}

Aichinger Dias L, Litz J, Garrison L, Martinez A, Barry K, Speakman T (2017) Exposure of cetaceans to petroleum products following the Deepwater Horizon oil spill in the Gulf of Mexico. Endang Species Res 33:119-125

Colegrove KM, Venn-Watson S, Litz J, Kinsel MJ and others (2016) Fetal distress and in utero pneumonia in perinatal dolphins during the Northern Gulf of Mexico unusual mortality event. Dis Aquat Org 119:1-16

DWH NRDA Trustees (Deepwater Horizon Natural Resource Damage Assessment) Trustees (2016) Deepwater Horizon oil spill: final programmatic damage assessment and restoration plan and final programmatic environmental impact statement. www.gulfspillrestoration. noaa.gov/restoration-planning/gulf-plan (accessed 23 Jan 2017)

Figueroa-Oliver LE, Cardona-Maldonado MA, GuzmánRamírez L, Jimenez-Marrero NM, Mignucci-Giannoni AA, Rodriguez-Lopez MA, Vargas-Gómez M (2000) Deadly effect intake and aspiration of diesel in a neonate Antillean manatee (Trichechus manatus): box clinical and post mortem findings. In: Abstracts of the 9th meeting of South American experts working on aquatic mammals (RT) and 3rd Congress of the Latin American Society of Aquatic Mammal Specialists (SOLAMAC), November 2000, Buenos Aires, Argentina, p 46

Geraci JR (1990) Physiologic and toxic effects on cetaceans. In: Geraci, JR, St. Aubin DJ (eds) Sea mammals and oil: confronting the risks. Academic Press, San Diego, CA, p 167-198

Geraci JR, St. Aubin DJ (eds) (1990) Sea mammals and oil: confronting the risks. Academic Press, San Diego, CA

Goodale DR, Hyman MAM, Winn HE (1979) Cetacean responses in association with REGAL SWORD oil spill. In: Edel RK, Hyman MA, Tyrell MF (eds) A characterization of marine mammals and turtles in the mid- and north Atlantic areas of the US outer continental shelf. Cetacean and Turtle Assessment Program Annual Report. University of Rhode Island, Kingston, RI, p 73-74. https://tethys.pnnl. gov/sites/default/files/publications/A_Characterization_ of_Marine_Mammals_and_Turtles.pdf (accessed 23 Jan 2017) 
Grose PL, Mattson JS (1977) The Argo Merchant oil spill: a preliminary scientific report. National Oceanic and Atmospheric Administration Environmental Research Laboratories, Boulder, CO

Harvey JT, Dahlheim ME (1994) Cetaceans in oil. In: Loughlin TR (ed) Marine mammals and the Exxon Valdez. Academic Press, San Diego, CA, p 257-264

Jessup DA, Leighton FA (1996) Oil pollution and petroleum toxicity to wildlife. In: Fairbrother A, Lock LN, Hoff GL (eds) Noninfectious diseases of wildlife. Iowa State University Press, Ames, IA, p 141-156

Johnson S, Ziccardi M (2006) Marine mammal oil spill response guidelines. NOAA Tech Memo. www.nmfs.noaa. gov/pr/pdfs/health/eis_appendixl.pdf (accessed 23 Jan 2017)

Leighton FA (1993) The toxicity of petroleum oils to birds. Environ Rev 1:92-103

Litz JA, Baran MA, Bowen-Stevens SR, Carmichael RH and others (2014) Review of historical unusual mortality events (UMEs) in the Gulf of Mexico (1990-2009): providing context for the multi-year northern Gulf of Mexico cetacean UME declared in 2010. Dis Aquat Org 112: 161-175

Loritz J (1991) The animal victims of the Gulf War. Physicians Soc Responsib Q 1991:221-225

Loughlin TR (1994) Tissue hydrocarbon levels and the number of cetaceans found dead after the spill. In: Loughlin TR (ed) Marine mammals and the Exxon Valdez. Academic Press, San Diego, CA, p 359-370

Massey JG (2006) Summary of an oiled bird response. J Exot Pet Med 15:33-39

Matkin CO, Ellis GM, Dahlheim ME, Zeh J (1994) Status of killer whales in Prince William Sound, 1985-1992. In: Loughlin TR (ed) Marine mammals and the Exxon Valdez. Academic Press, San Diego, CA, p 141-162

Mazet JAK, Newman SH, Gilardi KV, Tseng FS, Holcomb JB, Jessup DA, Ziccardi MH (2002) Advances in oiled bird emergency medicine and management. J Avian Med Surg 16:146-149

MMS (Minerals Management Service) (1983) Final environmental impact statement: proposed Southern California

Editorial responsibility: Louise Chilvers,

Palmerston, New Zealand lease offering, April 1984. US Dept of the Interior, Minerals Management Service, Los Angeles, CA. https://books. google.com/books?id=xSY3AQAAMAAJ\&printsec=front cover\#v=onepage \&q\&f=false

O'Hara TM, O'Shea TJ (2001) Toxicology. In: Dierauf LA, Gulland FMD (eds) CRC handbook of marine mammal medicine. CRC Press, Boca Raton, FL, p 471-502

Ozturk B (2002) Oil spills in the Turkish Straits System and the threats to marine biodiversity. In: Walmsley JG (ed) Proceedings of oil pollution and conservation of biodiversity, Porto Torres (Sardinia), p 39-48

Smith TG, Geraci JR, St. Aubin DJ (1983) Reaction of bottlenose dolphins, Tursiops truncatus, to a controlled oil spill. Can J Fish Aquat Sci 40:1522-1525

Smultea M, Wursig B (1995) Behavioral reactions of bottlenose dolphins to the Mega Borg oil spill, Gulf of Mexico 1990. Aquat Mamm 21:171-181

St. Aubin DJ, Lounsbury V (1988) Oil effects on manatees: evaluating the risks. In: Geraci JR, St. Aubin DJ (eds) Synthesis of effects of oil on marine mammals. OCS Study MMS 88-0049. Battelle Memorial Institute, Ventura, CA, p 246-258

Tseng FS (1999) Considerations in care for birds affected by oil spills. Semin Avian Exot Pet Med Toxicol 8:21-31

* US Department of Homeland Security (2011) On scene coordinator report: Deepwater Horizon oil spill. US Department of Homeland Security, US Coast Guard, Washington, DC. http://purl.fdlp.gov/GPO/gpo15255 (accessed 23 Jan 2017)

*Venn-Watson S, Colegrove KM, Litz J, Kinsel M and others (2015) Adrenal gland and lung lesions in Gulf of Mexico common bottlenose dolphins (Tursiops truncatus) found dead following the Deepwater Horizon oil spill. PLOS ONE 10:e0126538

Ziccardi MH, Wilkin SW, Rowles TK, Johnson SJ (2015) Pinniped and cetacean oil spill response guidelines. NOAA Tech Memo NMFS-OPR-52. US Dept of Commerce, NOAA, Silver Spring, MD

Zimmerman ST, Gorbics CS, Lowry LF (1995) Response activities. In: Loughlin TR (ed) Marine mammals and the Exxon Valdez. Academic Press, San Diego, CA, p 23-45

Submitted: January 4, 2017; Accepted: January 16, 2017

Proofs received from author(s): January 24, 2017 